Physiology

Albertoni Borghese, M.F. p77

Amazonas, R.B. p57

Behr, L. p65

Borenstein, N. p65

de Almeida Sanita, R. p57

Delgado, M.F. p77

Domin, J. p45

Fromont, G. p65

Gejyo, F. p87

Hama, H. p87

Harland, C. p17

Harper, L. p45

Harvey, B.J. p1

Hekmati, M. p65

Hendry, B.M. p45

Hosaka, K. p87
Hosojima, M. p87

lino, N. p87

Imai, N. p87

Kaseda, R. p87

Kashiwagi, Y. p45

Kawachi, H. p57

Kroeger, P.E. p35

Laborde, K. p65

Lelievre-Pegorier, M. p65

Lopes de Faria, J.B. p57

Ma, J. p35

Majowicz, M.P. p77

McEneaney, V. p1

Nakane, M. p35

Noel, L.-H. p65

Obayashi, H. p87
Ortiz, M.C. p77

Pusey, C.D. p45

Ruan, X. p35

Saito, A. p87

Sakimura, K. p87

Sato, H. p87

Sterin Speziale, N.B. p77

Takeda, T. p87

Tanuma, A. p87

Thomas, W. p1

Ueno, M. p87

Vidal, N.A. p77

Wrong, O. p17

Wu, F. p10

Wu-Wong, R. p35

Yamazaki, M. p87

\title{
Subject Index Vol. 107, 2007
}

Actin p45

Albuminuria p57

Aldosterone p1

Angiotensin receptor antagonist p57

Angiotensin-converting enzyme inhibitor p57

Anion-exchange resin p17

As4.1 cells p35

Cell therapy p65

Chronic nitric oxide synthase-induced hypertension $\mathrm{p} 77$

Cre/loxP p10

Cubilin p87

Cyclic AMP responsive element p35

Cytoskeleton reorganization $\mathrm{p} 45$

Dab2 p87
Dent's disease p87

Diabetic nephropathy p57

Endocytosis p87

Expression profiling p35

Glucocorticoid p1

Hypertension p57

Inducible targeting p10

Ischemia reperfusion injury p65

Kidney p65

Kidney-specific targeting p10

Megalin p87

Mesenchymal stem cell p65

Mineralocorticoid p1

Nephrin p57

Oestrogen p1

Paricalcitol p35
Phosphoinositide 3-kinase p45

Platelet-derived growth factor p45

Proximal tubule cells p87

Rapid responses $\mathrm{p} 1$

Renal failure p17

- sodium glucose cotransporter p77

Renin p35

Sheep p65

Short-chain fatty acids p17

Spontaneously hypertensive rats p57

Steroid p1

Transcription factors p35

van der Waals p17

Vitamin D p35

Water channel aquaporin-2 p77

Weak-base p17

\section{KARGER}

(c) 2007 S. Karger AG, Basel 